\title{
Novel laser-based techniques for monitoring of volcanoes
}

\author{
Paolo De Natale $\left({ }^{1}\right)$, Giuseppe De Natale $\left({ }^{2}\right)$, Gianluca Gagliardi $\left({ }^{1}\right)$, \\ Livio Gianfrani $\left({ }^{3}\right)$ and Alessandra S.D. Rocco $\left({ }^{1}\right)$ \\ (') Istituto Nazionale di Ottica Applicata, Comprensorio Olivetti, Pozzuoli (NA), Italy \\ ${ }^{(2)}$ Istituto Nazionale di Geofisica e Vulcanologia, Osservatorio Vesuviano, Napoli, Italy \\ $\left(^{3}\right)$ Dipartimento di Scienze Ambientali, Seconda Università di Napoli, \\ and INFM-Gruppo Coordinato Napoli 2, Caserta, Italy
}

\begin{abstract}
An overview of novel laser techniques suitable for volcanic monitoring, based on different kinds of infrared laser sources, is presented. Their main advantages and drawbacks are discussed focusing on the achievable sensitivity and precision levels in analysis of gaseous species. Some of the most recent experimental results obtained in laboratory development as well as in field tests of home-built laser spectrometers are reported. New perspectives in optical devices aimed at geochemical and geophysical applications are also considered.
\end{abstract}

Key words diode laser - absorption spectroscopy optical fiber

\section{Introduction}

The analysis of volcanic gases is widely recognised as a powerful tool to validate geological models relevant to reliable predictions of volcanic events (Baubron et al., 1991; Notsu et al., 1993). Indeed, the chemical composition of certain gases, in volcanic effluxes, may provide direct information on deep magmatic processes and hydrothermal circulation (Chiodini et al., 2003). In particular, the absolute concentration and the isotopic content of some molecular species gives an indication of sources and sinks of volcanic gases, whereas its time variation may be a consequence of changes in the status of a volcano. These changes can be due to chemical reactions

Mailing address: Dr. Gianluca Gagliardi, Istituto Nazionale di Ottica Applicata, Comprensorio Olivetti, Via Campi Flegrei 34, 80078 Pozzuoli (NA), Italy; e-mail: gagliardi@ino.it of magmatic gases with rocks or fluids occurring along their path to the surface.

With this in mind, the evolution of volcanic activity can be monitored using sensitive instrumentation for gas analysis (Chiodini et al., 2003). However, the compactness and ruggedness of field sensors are critical requirements for monitoring of volcanic areas, where the equipment is often exposed to high humidity, large temperature variations, and fumigation by corrosive gases. Furthermore, high precision and accuracy levels are necessary in order to retrieve significant information from experimental data. An ideal volcanic sensor would also allow for continuous, in situ gas concentration determination over long time periods, with unattended and remote operation.

So far, volcanic gases have been usually monitored by means of laboratory analysis methods, such as mass spectrometry and gas cromatography, which require in situ sampling, which is often impractical and hazardous. In addition, the time resolution of sampling-based methods may be not sufficient for some applications.

An alternative approach is given by optical techniques for remote-sensing, such as Differen- 
tial Optical Absorption Spectrometers (DOAS), LIDAR (Svanberg, 2002) or open-path FourierTransform Infrared Spectrometers (FTIR) (Oppenheimer, 2002). The first two methods provided good results in field volcanic measurements, as in the case of Galle et al. (2003), and Weibring et al. (2002), although some of these apparatus are bulky and expensive, and often require a time-consuming post-acquisition data processing. More recently, new instruments, based on UV-correlation and DOAS techniques, have been developed in a more compact and userfriendly fashion (Porter et al., 2002).

In the last few decades, the use of near-infrared room-temperature diode lasers for gas sensing has significantly increased (Werle, 1998). Compared to spectroscopic techniques that rely on incoherent sources as well as on lead-salt and solid-state lasers, semiconductor diode lasers offer the possibility to develop reliable and compact spectrometers, with reasonable costs. Also, they present several advantages in terms of tuneability, spectral selectivity and power consumption. The possible use of these devices in combination with optical fibers is particularly convenient for volcanic monitoring applications (Ginfrani et al., 2000). Thanks to the great advances in semiconductor and optoelectronic technologies, most of these features have been recently transferred to the midinfrared, with novel coherent radiation sources such as those based on difference-frequency generation and on quantum-cascade semiconductor structures (Tittel et al., 2002). In this spectral region, several atmospherically relevant molecules, like $\mathrm{H}_{2} \mathrm{O}, \mathrm{CO}_{2}, \mathrm{CH}_{4}$ and $\mathrm{SO}_{2}$, exhibit strong absorptions (Harvard Smithsonian Center for Astrophysics, 2003).

\section{Near-IR spectroscopy using DFB diode lasers}

Near-infrared diode laser sources, initially developed for telecom applications, are currently based on III-V semiconductor alloys. They operate in continuous mode, at room temperature, exhibiting single-mode emission in the 1$2 \mu \mathrm{m}$ range, with linewidths in the order of 10 $\mathrm{MHz}$ and output power of several mW. A sup- plementary DFB (distributed-feedback) structure also ensures very high spectral purity and mode-hop-free frequency tuning.

Diode-laser spectrometers rely on resonant absorption of coherent radiation by a gas sample, contained in an optical cell, whose transmission can be monitored by a pre-amplified room-temperature photodiode. According to Lambert-Beer Law, the transmitted power is related to the gas concentration $N$ (in molecules $/ \mathrm{cm}^{3}$ ) and to the cell length $L$ (in $\mathrm{cm}$ ), via the equation

$$
P(v)=P_{0} \exp \left[-S(T) g\left(v-v_{0}\right) N L\right]
$$

where $P_{0}$ is the incident power, $S(T)$ the transition linestrength (in $\mathrm{cm} /$ molecule), $v$ the laser frequency, $v_{0}$ the line-centre frequency and $g\left(v-v_{0}\right)$ the normalized line shape function.

In the last decade, several experimental schemes, mostly based on modulation of laser frequency, such as Wavelength- (WMS) or Frequency-Modulation Spectroscopy (FMS), have been developed in an attempt to increase detection sensitivity. Using these techniques, the retrieval of quantitative information from the absorption spectrum of a gas sample can be achieved by comparison with that of a reference cell, containing a known mixture. In this case, the chemical composition and thermodynamic conditions of the reference cell must be exactly the same as those of the sample under investigation. Any such difference may induce a systematic error in the measurement process, thus affecting the achievable accuracy, in spite of the high sensitivity. This is of particular importance in the case of gases from volcanoes, where large temperature and pressure variations are possible. Different approaches, based on a priori calibration of WMS or FMS signals (Goldstain and Adler-Golden, 1993), exhibit limited precision levels and are difficult to implement, and are thus ill-suited to environmental applications.

Recently, we demonstrated that measurements of absolute gas concentrations with high precision can be efficiently performed using a very simple method, based on direct absorption, which does not require any frequency modulation technique or calibration cell (Gagliardi et al., 2001). We employed an InGaAsP/InP DFB diode 
laser, emitting at a wavelength of $2-\mu \mathrm{m}$ and able to probe strong ro-vibrational lines of $\mathrm{CO}_{2}$ and $\mathrm{H}_{2} \mathrm{O}$. A Herriott-type multiple-reflection cell, with a path-length of $50 \mathrm{~m}$, was used as a gas cell. Absorption spectra were recorded for both species, and their concentration values were retrieved, through eq. (2.1), by measuring the integrated absorbances of the two absorption lines. This was possible after the product between the absorption pathlength and the linestrength had been measured using a certified gas mixture. Laboratory tests showed that a short-term reproducibility of $2 \%$ and an overall accuracy below $1 \%$ can be achieved in measurements in ambient $\mathrm{CO}_{2}$, within a wide range of concentration values (Gagliardi et al., 2002a). Simultaneous measurements of $\mathrm{CO}_{2}$ and $\mathrm{H}_{2} \mathrm{O}$ concentrations at similar precision levels were also demonstrated, a line pair of the two species being observed within one laser frequency scan.

One of the main advantages of such a nearIR laser spectrometer is its compatibility with telecom optical fibers, suitable for remote and in situ gas detection. Also, the principle of operation is completely independent of chemical composition and pressure of the gas sample. A portable version of the $2-\mu \mathrm{m}$ spectrometer was subsequently developed and tested to monitor gaseous emissions in volcanic areas, during a field campaign at Vulcano Island and Solfatara volcano, in Italy, during July and November, 2002 (Rocco et al., 2004). The experimental setup is schematically represented in fig. 1 . The spectrometer is split into two parts, mounted on different breadboards, and connected by a telecom, single-mode, 30-m-long optical fiber. The laser source and collimating optics are mounted on one breadboard while the gas detection system on a another one, with a large hole in the centre which allows the gas to flow through the cell. In this way, remote measurements are possible at different sites across a volcanic area. In addition, a custom-built, open-path multiple-reflection cell, with a 20 -m pathlength, was used for direct analysis of fumarolic effluxes without requiring any sampling procedure. Figure 2 shows an example of absorption spectrum. It corresponds to the $R(34)$ rotational line of the $v_{1}+2 v_{2}+v_{3} \mathrm{CO}_{2}$ combination band, and to the $15_{0.15} \rightarrow 14_{0.14}$ line of the $v_{2}+v_{3} \mathrm{H}_{2} \mathrm{O}$ band, around $5000 \mathrm{~cm}^{-1}$. The absorption signal was recorded at the Solfatara crater, directly on the flux of a small fumarole, scanning the laser frequency around a $\mathrm{CO}_{2}-\mathrm{H}_{2} \mathrm{O}$ line pair, while the

\section{BB1}

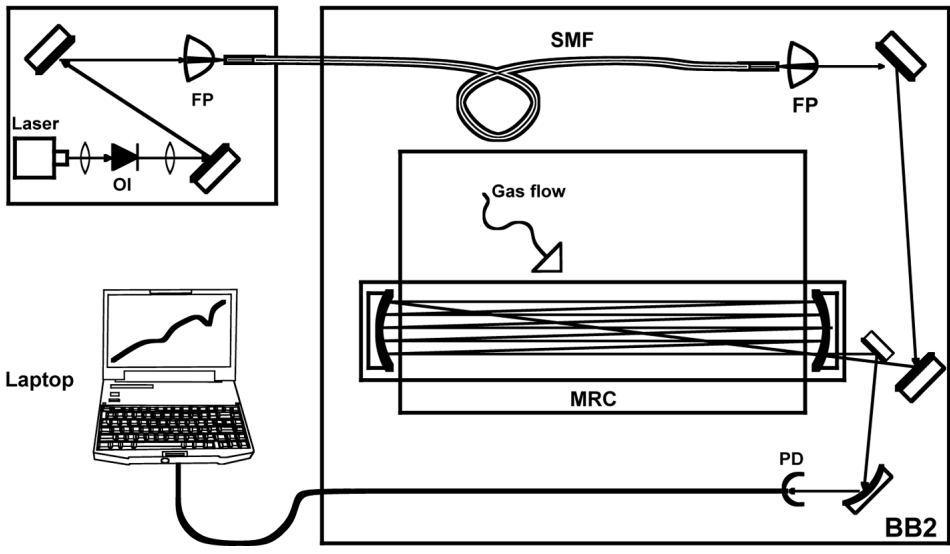

Fig. 1. Sketch of the experimental arrangement of the portable 2- $\mu \mathrm{m}$ spectrometer. OI - Optical Isolator; SMF Single Mode Fiber; FP - Fiber Port; MRC - Multiple-Reflection Cell; PD - photodiode; BB1 - breadboard 1 $\left(60 \times 60 \mathrm{~cm}^{2}\right) ; \mathrm{BB} 2-$ breadboard $2\left(70 \times 40 \mathrm{~cm}^{2}\right)$. 

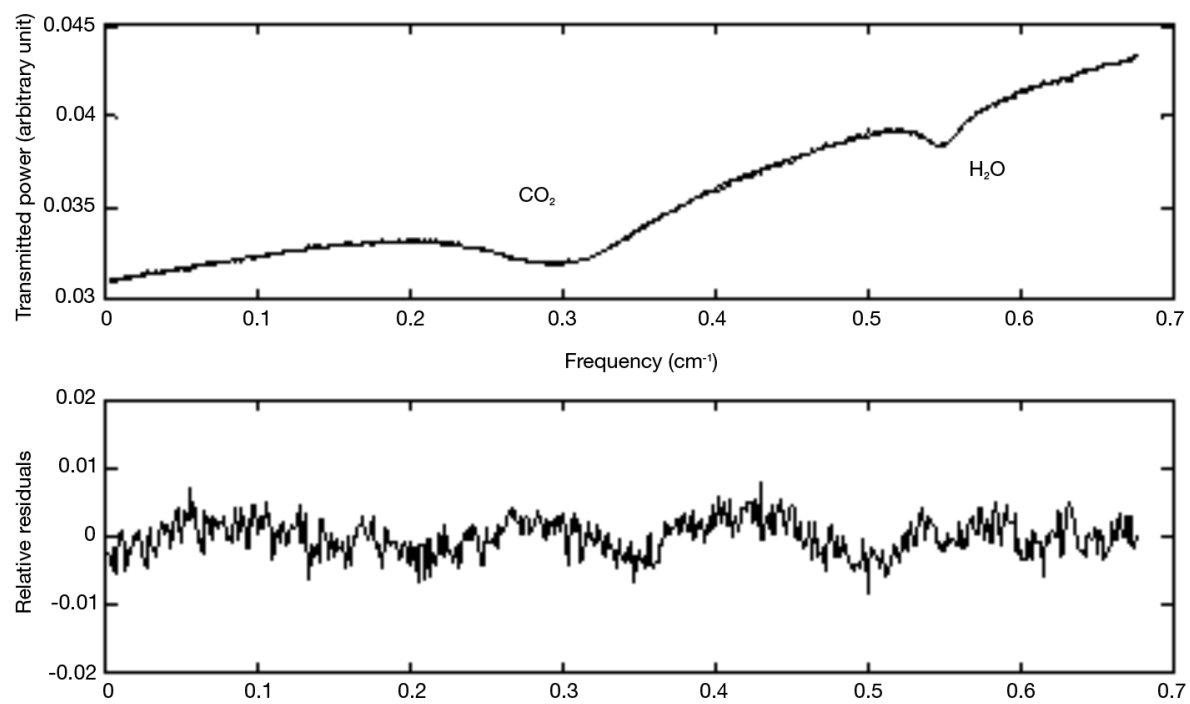

Fig. 2. Direct absorption measurement of $\mathrm{CO}_{2}$ and $\mathrm{H}_{2} \mathrm{O}$ performed for a small fumarole at the Solfatara volcano (Italy). The continuous line represents the Lorentian fit curve.

experimental spectra were continuously transferred to a laptop computer and analysed by a LABVIEW program. Furthermore, $\mathrm{CO}_{2}$ and $\mathrm{H}_{2} \mathrm{O}$ concentrations could be monitored in ambient air for several minutes, with a typical uncertainty of a few $\%$, thus demonstrating real-time analytical capabilities of our spectrometer in hostile environmental conditions (Rocco et al., 2004). Thanks to its low power consumption and ruggedness, the apparatus was transported almost everywhere in the selected volcanic sites. Indeed, substitution of optical or mechanical components was never necessary during operation in the whole campaign. The main drawback of our diode-laser based spectrometer is the influence of temperature fluctuations on measured concentration values. Due to the molecular linestrength dependence on Boltzmann distribution of population among energy levels, variations in the order of $3 \% /{ }^{\circ} \mathrm{C}$ for water vapor, and less than $1 \% /{ }^{\circ} \mathrm{C}$ for carbon dioxide are expected. Nevertheless, the gas cell temperature was continuously monitored and acquired and, when necessary, its values were used to correct the corresponding small changes in the integrated absorbances.

\section{Mid-IR spectroscopy with quantum- cascade lasers and difference-frequency based spectrometers}

The advantages of direct absorption detection can be better exploited when one moves towards longer wavelengths. Indeed, most atmospheric molecules present stronger absorption bands, due to their fundamental vibrations, above $3 \mu \mathrm{m}$. That allows for sensitive detection of low abundance gases, like $\mathrm{CH}_{4}, \mathrm{SO}_{2}$ and $\mathrm{N}_{2} \mathrm{O}$, at their ambient concentration levels. For this reason, much effort has been directed towards the development of new coherent radiation sources emitting in the mid-IR spectral region. Among them are Quantum-Cascade Lasers (QCL), covering the interval from 3.5 to $24 \mu \mathrm{m}$, rare-earth-doped DFB fiber lasers, in the $1 \mu \mathrm{m}$ to $1.5 \mu \mathrm{m}$ range, and Optical Parametric Oscillators (OPO) or Difference-Frequency Generation (DFG) in periodically-poled crystals, between 2 and $5 \mu \mathrm{m}$.

Quantum cascade lasers were invented in 1994, at Lucent Technologies (Murray Hill, NJ) and are essentially based on a multiple miniband structure resulting from deposition of ultrathin alternating layers of semiconductor materi- 
als. Electron transitions occur between different quantum well levels, in each mini-band, with many-photon emission (Faist et al., 1994). The major limitation of such lasers is the need for cryogenic cooling in order to have continuouswave (cw) operation. Alternatively, they can be used at room-temperature in pulsed mode (Faist et al., 1998). Nevertheless, QCLs usually exhibit output power of $50-100 \mathrm{~mW}$ and intrinsic emission linewidth well below $1 \mathrm{MHz}$, with the possibility of a DFB design for high spectral purity and continuous wavelength tuning. Furthermore, cw operation of a quantum-cascade device, up to $246 \mathrm{~K}$ on a Peltier cooler, has recently been achieved (Hofstetter et al., 2001).

After the advent of quantum cascade lasers, several QCL-based spectrometers were successfully used, either in pulsed or continuous mode, for absorption spectroscopy as well as isotopic detection of species whose transitions are not accessible to conventional room-temperature diode lasers (Webster et al., 2001; Kosterev and Tittel, 2002). Our group recently developed a novel spectrometer relying on a cw DFB QCL at a wavelength of $8.06 \mu \mathrm{m}$, manufactured at Lucent Technologies Labs. In the experimental set-up, described in Gagliardi et al. (2002b), the laser was placed in a liquid- $\mathrm{N}_{2}$ cryostat, and stabilised by an active temperature controller. The laser beam was coupled to a $17-\mathrm{cm}$ long absorption cell, filled with the gas sample, whose transmission was monitored by a liquid- $\mathrm{N}_{2}$ cooled $\mathrm{HgCdTe}$ detector. The QCL spectrometer enabled us to detect the presence of very low $\mathrm{CH}_{4}$ concentration. Indeed, several methane absorption spectra were recorded at sub-Torr pressures, in correspondence of the strong $P(10) A 2(1)$ A1(1) line, belonging to the $v_{4}$ fundamental band. Some of these spectra, with increasing absorbance, are shown in fig. 3, for different gas pressures in the cell. A wavelength-modulation spectroscopic technique, with phase-sensitive 1st-harmonic demodulation, was also implemented in order to detect $\mathrm{CH}_{4}$ isotopomers. An example of simultaneous recording of ${ }^{13} \mathrm{CH}_{4}$ and ${ }^{12} \mathrm{CH}_{4}$, for natural isotopic abundance methane, is given in fig. 4. The spectra were observed within a single QCL frequency scan, amounting to $1 \mathrm{GHz}$. Furthermore, simultaneous detection of nitrous oxide and its isotopomers ${ }^{14} \mathrm{~N}^{15} \mathrm{~N}^{16} \mathrm{O}$, ${ }^{15} \mathrm{~N}^{14} \mathrm{~N}^{16} \mathrm{O},{ }^{14} \mathrm{~N}^{14} \mathrm{~N}^{18} \mathrm{O}$ and ${ }^{14} \mathrm{~N}^{14} \mathrm{~N}^{17} \mathrm{O}$ was possible, in the same spectral region, with similar performances (Gagliardi et al., 2002b). An example is reported in fig. 5 . In these operational conditions, a sensitivity level corresponding to a minimum detectable pressure of few mTorr was estimated, for pure methane and nitrous oxide, in a 1-m absorption pathlength. In addition, a signal repro-
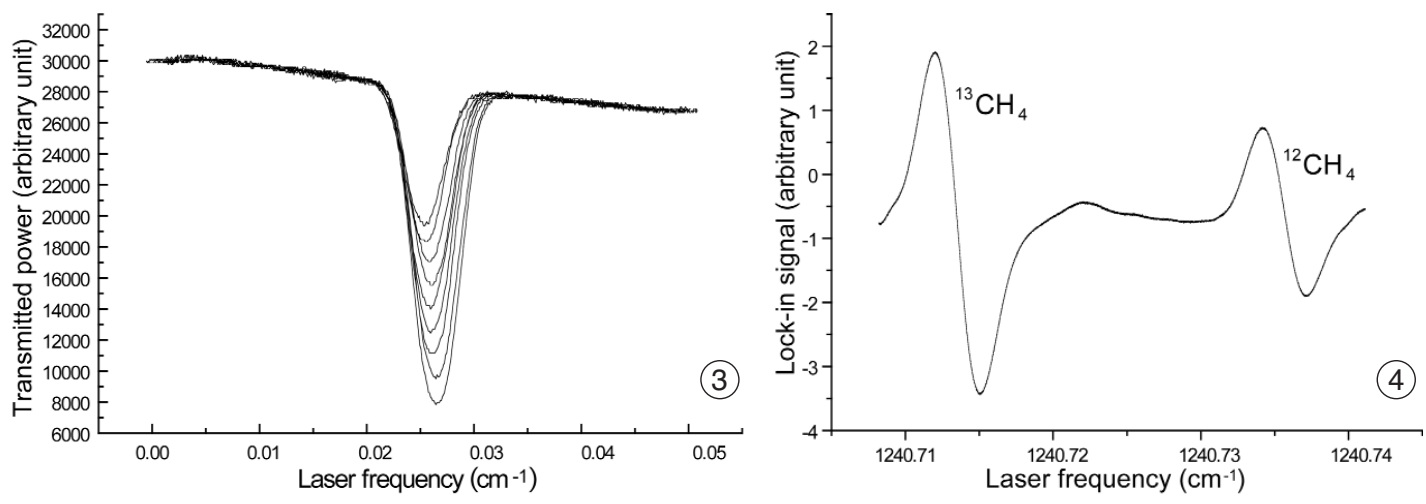

Fig. 3. Direct absorption spectrum of pure methane, around $1241 \mathrm{~cm}^{-1}$. The gas pressure in the cell was varied from 100 to 400 mTorr.

Fig. 4. Simultaneous detection of ${ }^{13} \mathrm{CH}_{4}$ and ${ }^{12} \mathrm{CH}_{4}$, in natural isotopic abundance $(1.1 \%$ and $98.9 \%$, respectively), in the presence of 150 mTorr of pure methane. 


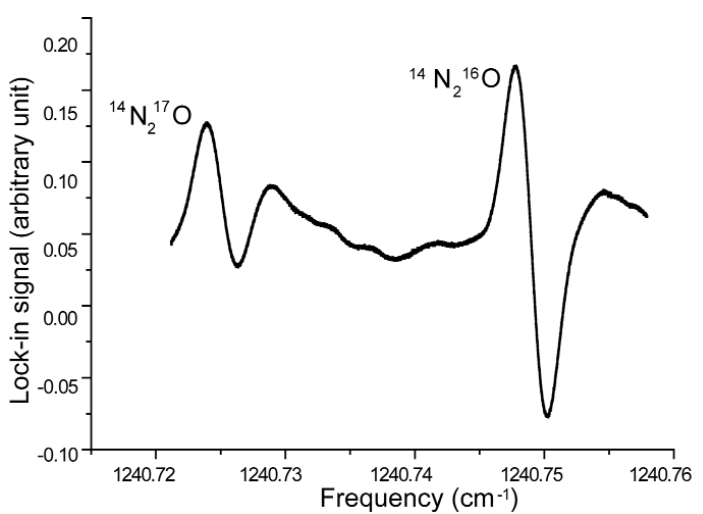

Fig. 5. First-harmonic absorption spectrum of ${ }^{14} \mathrm{~N}^{14} \mathrm{~N}^{17} \mathrm{O}$ and ${ }^{14} \mathrm{~N}^{14} \mathrm{~N}^{16} \mathrm{O}(0.37 \%$ and $99 \%$, respectively). The $\mathrm{N}_{2} \mathrm{O}$ pressure was equal to 80 mTorr.

ducibility better than $1 \%$ was demonstrated in detection of all species. This feature is relevant to a possible use of the $8-\mu \mathrm{m}$ spectrometer for measurements of the ${ }^{13} \mathrm{C} /{ }^{12} \mathrm{C}$ and ${ }^{15} \mathrm{~N}^{14} \mathrm{~N},{ }^{18} \mathrm{O} /{ }^{16} \mathrm{O}$, ${ }^{17} \mathrm{O} /{ }^{16} \mathrm{O}$ isotope ratios in $\mathrm{CH}_{4}$ and $\mathrm{N}_{2} \mathrm{O}$, respectively.

Although the results obtained in our laboratory tests are encouraging, some drawbacks come from the use of a quantum cascade laser. For instance, the cryogenic system used for laser operation is bulky and expensive, while the highcurrent supply, usually needed for laser driving, makes its use somewhat difficult. As a consequence, considerable effort is still required in order to make this kind of spectrometer compact and well suited for field measurements.

A novel apparatus, based on difference-frequency generation in a periodically-poled lithium niobate crystal, is currently being developed in our lab. Mixing an Er-fiber-amplified diode laser, emitting at $1.55 \mu \mathrm{m}$, and an extended-cavity $1.05-\mu \mathrm{m}$ diode laser, externally amplified by an Yb-fiber, we expect to produce coherent radiation around a wavelength of $3 \mu \mathrm{m}$, with powers up to $10 \mathrm{~mW}$. Such a DFG spectrometer would satisfy some crucial requirements for spectroscopy, such as high spectral resolution, high power and wide tuneability. Indeed, its spectral coverage ranges from 2.9 to $3.5 \mu \mathrm{m}$. This is of great relevance if we consid- er the current lack of laser sources in the region between 2.2 and $3.5 \mu \mathrm{m}$, where strong absorption bands of $\mathrm{N}_{2} \mathrm{O}$ and $\mathrm{CH}_{4}$ as well as of $\mathrm{H}_{2} \mathrm{O}$, $\mathrm{NH}_{3}$ and $\mathrm{NO}_{2}$ take place. It is worth noting that neither QCLs can presently cover this spectral window, due to manufacturing difficulties.

\section{Conclusions and future perspectives}

Several spectroscopic set-ups, based on different laser sources, have been reviewed. Some experimental results were presented on monitoring of $\mathrm{CO}_{2}$ and $\mathrm{H}_{2} \mathrm{O}$ emitted by volcanic fumaroles, using a compact and portable spectrometer operating at $2 \mu \mathrm{m}$. Using such a spectrometer, continuous, fast and in situ detection of these species was possible, measuring their concentrations with precision levels of a few $\%$. For future developments, novel near-IR laser sources, such as Tm-doped fiber-based lasers, are also being considered as an alternative to diode lasers, especially in view of their possible integration in an optical fiber network for multiple-point, simultaneous monitoring of gas concentrations. Using the same fiber, the absorption spectrometer can also be combined with fiber Bragg-grating sensors for local measurements of strain and temperature (Rao, 1997). Such a network would be particularly relevant to the implementation of reliable methods for volcanic surveillance.

Alternative approaches for concentration measurements were also mentioned, such as Quantum-Cascade Laser (QCL) and Difference-Frequency-Generation (DFG) based spectrometers in the mid-IR. They exhibit significant advantages for analysis of gases whose natural abundance is extremely low. In particular, using a QCL at $8 \mu \mathrm{m}$, we demonstrated the potentiality of our spectrometer for detection of $\mathrm{CH}_{4}, \mathrm{~N}_{2} \mathrm{O}$ and their isotopomers, with high sensitivity and resolution.

\section{Acknowledgements}

This work was supported by the «Gruppo Nazionale per la Vulcanologia» (GNV), through a Coordinated Project in the Framework Program 2000-2002. 


\section{REFERENCES}

Baubron, J.C., P. Allard, J.C. Sabroux, D. Tedesco and J.P. ToutAIN (1991): Soil gas emanations as precursory indicators of volcanic eruptions, J. Geol. Soc. London, 148, 571-576.

Chiodini, G., M. Todesco, S. Caliro, C. Del Gaudio, G. MACEDONIO and M. Russo (2003): Magma degassing as a trigger of bradyseismic events: the case of Phlegraean Fields (Italy), Geophys. Res. Lett., 30 (8), 1434, doi: 10.1029/2002GL016790.

FAist, J., F. CAPASSO, D.L. SivCO, C.Sirtori, A.L. HutChinson and A.Y. CHO (1994): Quantum cascade laser, Science, 264, 553-555.

Faist, J., F. CAPAsso, D.L. Sivco, A.L. Hutchinson, S.G. CHu and A.Y. Сно (1998): Short wavelength $(\lambda \sim 3.4$ $\mu \mathrm{m})$ quantum cascade laser based on strained compensated InGaAs/AlInAs, Appl. Phys. Lett., 72 (6), 680682 .

Gagliardi, G., R. Restieri, G. De Biasio, P. De Natale, F. COTRUFO and L. GIANFrANI (2001): Quantitative diodelaser absorption spectroscopy near $2 \mu \mathrm{m}$ and high precision measurements of $\mathrm{CO}_{2}$ concentration, Rev. Sci. Inst., 72, 4228 .

Gagliardi, G., R. Restieri, G. Casa and L. Gianfrani (2002a): Concentration measurements and isotopic analysis using diode laser spectroscopy: applications to volcanic gas monitoring, Opt. Lasers Eng., 37, 131-142.

Gagliardi, G., F. Tamassia, P. De Natale, C. Gmachl, F. Capasso, D.L. Sivco, J.N. Baillargeon, A.L. Hutchinson and A.Y. Cho (2002b): Sensitive detection of methane and nitrous oxide isotopes using a cw quantum cascade laser, Eur. Phys. J. D, 19 (3), 327332.

Galle, B., C. Oppenheimer, A. Geyer, A.J.S. Mcgonigle, M. Edmonds and L.A. Horrocks (2003): A miniaturised ultraviolet spectrometer for remote sensing of $\mathrm{SO}_{2}$ fluxes: a new tool for volcano surveillance, J. Volcanol. Geotherm. Res., 119, 241-254.

Gianfrani, L., P. De Natale and G. De Natale (2000): Remote sensing of volcanic gases with a DFB-laser-based fiber spectrometer, Appl. Phys. B, 70, 467-470.

Goldstein, N. and S. ADLER-GoLdEN (1993): Long-atmospheric-path measurements of near-visible absorption lines of $\mathrm{O}_{2}$ isotopes and $\mathrm{H}_{2} \mathrm{O}$ with a prototype $\mathrm{AlGaAs}$ laser transceiver system, Appl. Opt., 32, 5849-5855.

HARVARD SMithSONIAN CENTER FOR Astrophysics (2003): The Hitran Database 2003 (on line at: http://www.hitran.com).
Hofstetter, D., M. Beck, T. Aellen, J. Faist, U. OesterLE, M. Ilegems, E. Gini and H. Melchior (2001): Continuous wave operation of a $9.3 \mu \mathrm{m}$ quantum cascade laser on a Peltier cooler, Appl. Phys. Lett., 78, 1964 1966.

Kosterev, A.A. and F.K. Tittel (2002): Chemical sensors based on quantum cascade lasers, IEEE J. Quantum Electr., 38, 582-591.

Notsu, K., T. Mori, G. Igarashi, Y. TohJima and H. WAKITA (1993): A new tool for remote measurement of SO of volcanic gas, Geochem. J., 27, 361-366.

Oppenheimer, C., M. Burton, J. Durieux and D.M. Pyle (2002): Open-path Fourier transform spectroscopy of gas emissions from Oldoinyo Lengai volcano, Tanzania, Opt. Lasers Eng., 37, 203-214.

Porter, J.N., K.A. Horton, P.J. Mouginis-Mark, B. Lienert, S.K. Sharma and E. LAU (2002): Sun photometer and lidar measurements of the plume form the Hawaii Kilauea Volcano Pu'uO'o vent: aerosol flux and $\mathrm{SO}_{2}$ lifetime, Geophys. Res. Lett., 29 (16), 10.1029/ 2002GL014744.

RAO, Y.J. (1997): In-fibre Bragg grating sensors, Meas. Sci. Technol., 8, 355-375.

Rocco, A., G. De Natale, P. De Natale, G. Gagliardi and L. GiANFRANi (2004): A diode laser based spectrometer for in-situ measurements of volcanic gases, Appl. Phys. $B, \mathbf{7 8}, 235-240$.

SvANBERG, S. (2002): Geophysical gas monitoring using optical techniques: volcanoes, geothermal fields and mines, Opt. Lasers Eng., 37, 245-266.

TitTel, F.K., D. Richter and A. Fried (2002): Mid-infrared laser applications in spectroscopy, in Solid-State MidInfrared Laser Sources, edited by I.T. SOROKINA and K. VODOPYANOV (Springer Verlag), 445-511.

Webster, C.R., G. Flesch, D. Scott, J. Swanson, R. May, W. Woodward, C. Gmachl, F. Capasso, D. Sivco, J. Baillargeon, A. Hutchinson and A. ChO (2001): Quantum-cascade laser measurements of stratospheric methane $\left(\mathrm{CH}_{4}\right)$ and nitrous oxide $\left(\mathrm{N}_{2} \mathrm{O}\right)$, Appl. Opt., 40, 321-326.

Weibring, P., J. Swartling, H. Edner, S. Svanberg, T. Caltabiano, D. Condarelli, G. Cecchi and L. PanTANI (2002): Optical monitoring of volcanic sulphur dioxide emissions-comparison between four different remote-sensing spectroscopic techniques, Opt. Lasers Eng., 37, 267-284.

WERLE, P. (1998): A review of recent advances in semiconductor laser based gas monitors, Spect. Acta A, 54,197 236. 